\title{
Response to Morreale
}

\author{
Nelson Orta ${ }^{1,2} \mathbb{D} \cdot$ Amado Alvarado $^{3}$
}

Received: 14 September 2021 / Revised: 14 September 2021 / Accepted: 22 September 2021 / Published online: 14 October 2021

(c) The Author(s), under exclusive licence to International Pediatric Nephrology Association 2021

\section{Dear Editors,}

As a response to the letter to the editor with additional and important information from Drs. A Morreale and ML Casciana, who report a new pediatric case of $\mathrm{C} 19$ and onset of nephrotic syndrome (NS), we want to make some comments.

Certainly, in 2020, 2 reports were published (including our case) almost simultaneously of pediatric cases of the two entities and there could be relevance in their association. In our article, we preferred to keep an open mind before making a definitive statement of a possible relationship. Secondly, there is the relevant fact that in adult patients with $\mathrm{C} 19$ and severe kidney involvement, significant proteinuria has been found [1].

It is not clear whether the NS is secondary to C19; however, there is a possible association in light of recent reports [2] and we know this topic is under further investigation. Another related and important aspect, and also highly worrying, is the observation of the development of NS in some people vaccinated with the mRNA-SARS-CoV-2 vaccine [3]. It could be speculated that the virus or related particles could have provoked kidney lesions that affected the glomerular filtration barrier and produced proteinuria. However, further studies are necessary, and some are already in progress. Additionally, it is important to investigate routine kidney function and the level of proteinuria in patients with C19 in order to obtain additional data and, eventually, more insight into this issue.

\section{References}

1. Gross O, Moerer O, Weber M, Huber TB, Scheithauer S (2020) COVID-19-associated nephritis: early warning for disease severity and complications? Lancet 395:E87-E88. https://doi.org/10.1016/ S0140-6736(20)31041-2

2. Angeletti A, Drovandi S, Sanguineri F, Santaniello M et al (2020) COVID-19 in children with nephrotic syndrome on anti-CD20 chronic immunosuppression. Clin J Am Soc Nephrol 15:14941495. https://doi.org/10.2215/cjn.06400420

3. Bomback A, Kudose S, D’Agati V (2021) De novo and relapsing glomerular diseases after C-19 vaccination: what do we know so far? Am J Kidney Dis. https://doi.org/10.1053/j.ajkd.2021.06.004

Publisher's Note Springer Nature remains neutral with regard to jurisdictional claims in published maps and institutional affiliations.
Nelson Orta

nelson.orta@gmail.com

University of Carabobo, Valencia, Venezuela

2 University Hospital of Gandia, Valencia, Spain

3 ICU General Hospital, Ecuadorian Institute of Social Security, IESS, Quito, Ecuador 